\title{
Compressive behaviour at High Temperatures of Fibre Reinforced Concretes
}

\author{
S. O. Santos, J. P. C. Rodrigues, R. Toledo, R. V. Velasco
}

This paper summarizes the research that is being carried out at the Universities of Coimbra and Rio de Janeiro, on fibre reinforced concretes at high temperatures. Several high strength concrete compositions reinforced with fibres (polypropylene, steel and glass fibres) were developed. The results of compressive tests at high temperatures $\left(300^{\circ} \mathrm{C}, 500^{\circ} \mathrm{C}\right.$ and $\left.600{ }^{\circ} \mathrm{C}\right)$ and after heating and cooling down of the concrete are presented in the paper. In both research studies, the results indicated that polypropylene fibers prevent concrete spalling.

Keywords: Concrete, high temperatures, compressive strength, spalling, polypropylene fibres, steel fibres, glass fibres.

\section{Introduction}

In the last 20 years, concrete has been developed to perform better in all situations. The changes made in mixture composition (lower water content, use of superplasticizers, optimization of grain size distribution, use of particles with pozzolanic activity, addition of fibers, etc.) have led to striking improvements in many properties such as strength, rheology of fresh concrete, ductility and compactness. Compactness usually results in better durability, but it may also lead to the brittle behavior of high-performance concrete (HPC) in fire conditions. Under certain thermal and mechanical stresses, HPC may spall [1].

Spalling is the violent or non-violent breaking off of layers or pieces of concrete from the surface of a structural element when it is exposed to high and rapidly rising temperatures, as experienced in fires [2]. It results from two concomitant processes: (i) the thermo-mechanical process associated with the thermal expansion/shrinkage gradients that occur within the element being heated, and (ii) the thermo-hydral process that generates high-pressure fields of gas (water vapour and trapped air) in the porous network [3].

Fires have occurred in several tunnels in Europe in the past years. They have caused loss of life, as well as significant damage to the concrete structure. Some of these tunnels, such as the Channel Tunnel and the Great Belt Tunnel, were built recently. This shows that spalling phenomenon is not yet sufficiently understood for it to be prevented in the construction process.

This paper intends to contribute to the understanding of concrete behavior at high temperatures, and to the characterization of the spalling phenomenon, through the development of concretes with improved fire behavior. A Portuguese study and a Brazilian study are described, which were carried out to develop fiber concrete compositions with better fire behavior.

\section{Experimental studies}

\subsection{Portuguese tests}

Studies are in progress in the Laboratory of Testing Materials and Structures of the University of Coimbra to develop high-strength concretes (HSC) with improved fire behavior. Three compositions of concrete are presented in this paper: one without fibers, one with both steel and polypropylene fibers, and a third one with glass fibers. Compressive strength tests were carried out at high temperatures on cylindrical specimens of these three concrete compositions [4].

\section{Concrete compositions}

Table 1 provides details of the three compositions. All compositions contained Portland cement (CEM) type II 42,5R, superplasticizer (SP) SIKA $3002 \mathrm{HE}$, limestone filler (LF) and four different aggregates: fine sand (FS) with a fineness modulus of 1.87, coarse aggregate (CA) with maximum size of $9.5 \mathrm{~mm}$ and two calcareous crushed stone (CS1 and CS2 with maximum sizes of $12.5 \mathrm{~mm}$ and $25 \mathrm{~mm}$, respectively).

The compositions differ only in the fiber type, or lack of them. The first composition (HSC) had no fibers, while the second contained DRAMIX RC ZP305 steel fibers (SF) $30 \mathrm{~mm}$ in length, $0.55 \mathrm{~mm}$ in diameter, a length/diameter ratio of 55 , tensile strength of $1100 \mathrm{MPa}$, together with

Table 1: Concrete compositions (per $\mathrm{m}^{3}$ )

\begin{tabular}{|l|c|c|c|c|c|c|c|c|c|c|c|}
\hline & $\begin{array}{c}C E M \\
{[\mathrm{~kg}]}\end{array}$ & $\begin{array}{c}C S 1 \\
{[\mathrm{~kg}]}\end{array}$ & $\begin{array}{c}C S 2 \\
{[\mathrm{~kg}]}\end{array}$ & $\begin{array}{c}C A \\
{[\mathrm{~kg}]}\end{array}$ & $\begin{array}{c}F S \\
{[\mathrm{~kg}]}\end{array}$ & $\begin{array}{c}L F \\
{[\mathrm{~kg}]}\end{array}$ & $W / C$ & $\begin{array}{c}S P \\
{[\% \mathrm{CEM}]}\end{array}$ & $\begin{array}{c}P F \\
{[\mathrm{~kg}]}\end{array}$ & $\begin{array}{c}S F \\
{[\mathrm{~kg}]}\end{array}$ & $\begin{array}{c}G F \\
{[\mathrm{~kg}]}\end{array}$ \\
\hline HSC & 400 & 600 & 321 & 230 & 470 & 200 & 0.3 & 2.9 & - & - & - \\
\hline HSCSPF & 400 & 600 & 321 & 230 & 470 & 200 & 0.3 & 11.6 & 1 & 70 & - \\
\hline HSCGF & 400 & 600 & 321 & 230 & 470 & 200 & 0.3 & 11.6 & - & - & 1.5 \\
\hline
\end{tabular}


Table 2: Compressive resistance classes

\begin{tabular}{|c|c|c|c|c|c|}
\hline & $\begin{array}{c}f_{c} \\
{[\mathrm{MPa}]}\end{array}$ & $\begin{array}{c}f_{c m} \\
{[\mathrm{MPa}]}\end{array}$ & $\begin{array}{c}f_{c k} \\
{[\mathrm{MPa}]}\end{array}$ & Resistance Class & $\begin{array}{c}\text { Compression load }\left(0.7 f_{c d}\right) \\
{[\mathrm{kN}]}\end{array}$ \\
\hline \multirow{3}{*}{ HSC } & 73.04 & \multirow{3}{*}{71.33} & \multirow{3}{*}{63.33} & \multirow{3}{*}{ C50/60 } & \multirow{3}{*}{130.5} \\
\hline & 72.25 & & & & \\
\hline & 68.69 & & & & \\
\hline \multirow{3}{*}{ HSCPSF } & 75.79 & \multirow{3}{*}{76.21} & \multirow{3}{*}{68.21} & \multirow{3}{*}{ C55/67 } & \multirow{3}{*}{140.6} \\
\hline & 77.18 & & & & \\
\hline & 75.65 & & & & \\
\hline \multirow{3}{*}{ HSCGF } & 65.19 & \multirow{3}{*}{64.16} & \multirow{3}{*}{56.16} & \multirow{3}{*}{$\mathrm{C} 45 / 55$} & \multirow{3}{*}{115.8} \\
\hline & 57.04 & & & & \\
\hline & 70.23 & & & & \\
\hline
\end{tabular}

DURO-FIBRIL polypropylene fibers (PF), $31 \mu \mathrm{m}$ in diameter and $6 \mathrm{~mm}$ in length (HSCPSF); the third composition contained VIMACRACK glass fibers (GF), $12 \mathrm{~mm}$ in length and $14 \mu \mathrm{m}$ in diameter (HSCGF).

Table 2 shows the resistance classes for each concrete composition, obtained in compressive strength tests at room temperature, after 28 days, carried out according to the European Standard EN 206-1 (2000). This table also incorporates the values corresponding to a compression load of $0.7 \mathrm{f}_{\mathrm{cd}}$, applied to the specimens during the heating process, in the compressive strength tests at high temperatures. This load was intended to simulate the maximum load that the concrete is usually subjected to in building structures.

When exposed to high temperatures, the polypropylene fibers form pathways that allow the steam to escape, thereby reducing the pressure accumulated in the porous network of the concrete element, while the steel fibers increase the ductility of the concrete, making it more mechanically and thermally resistant. Glass fibers were included in a concrete composition to assess to what extent these fibers can replace the polypropylene and steel fibers, taking into account the concrete strength at high temperatures.

\section{Specimens}

The specimens were cylinders $75 \mathrm{~mm}$ in diameter $(\varnothing)$ and $225 \mathrm{~mm}$ in height $(h)$, with $h / \varnothing$ ratio 3 .

Five type K thermocouples (Cromo-Alumel) $0.5 \mathrm{~mm}$ in diameter were placed within the specimen and on its surface to measure the temperature during high temperatures tests.

The location of the thermocouples was defined according to the recommendations of RILEM TC-200 HTC [5].

\section{Test procedure}

The test system used is presented in Fig. 1. It consisted of an AMSLER compression machine with a capacity of $5 \mathrm{MN}$ (a), a cylindrical furnace with an internal diameter of $90 \mathrm{~mm}$ and $300 \mathrm{~mm}$ in height, capable of temperatures up to $1200^{\circ} \mathrm{C}$ (b) and a TML TDS-601 datalogger for data acquisition (force, displacement, and furnace and specimen temperatures) (c).

The test procedures followed the RILEM TC-200 HTC recommendations [5]. A load equal to $70 \%$ of the design value of concrete compressive strength at room temperature $\left(0.7 \mathrm{f}_{\mathrm{cd}}\right)$ was initially applied to the specimen. When the load level was reached, the specimen was heated at a rate of $3{ }^{\circ} \mathrm{C} / \mathrm{min}$, until the desired level of temperature was reached. Three maximum temperatures were tested: $300{ }^{\circ} \mathrm{C}, 500{ }^{\circ} \mathrm{C}$ and $600{ }^{\circ} \mathrm{C}$. The temperature was deemed to be reached when the average temperatures registered by the three specimen thermocouples on the surface matched the temperature of the furnace. The specimen was then kept at that temperature for an hour to stabilize. The temperature difference

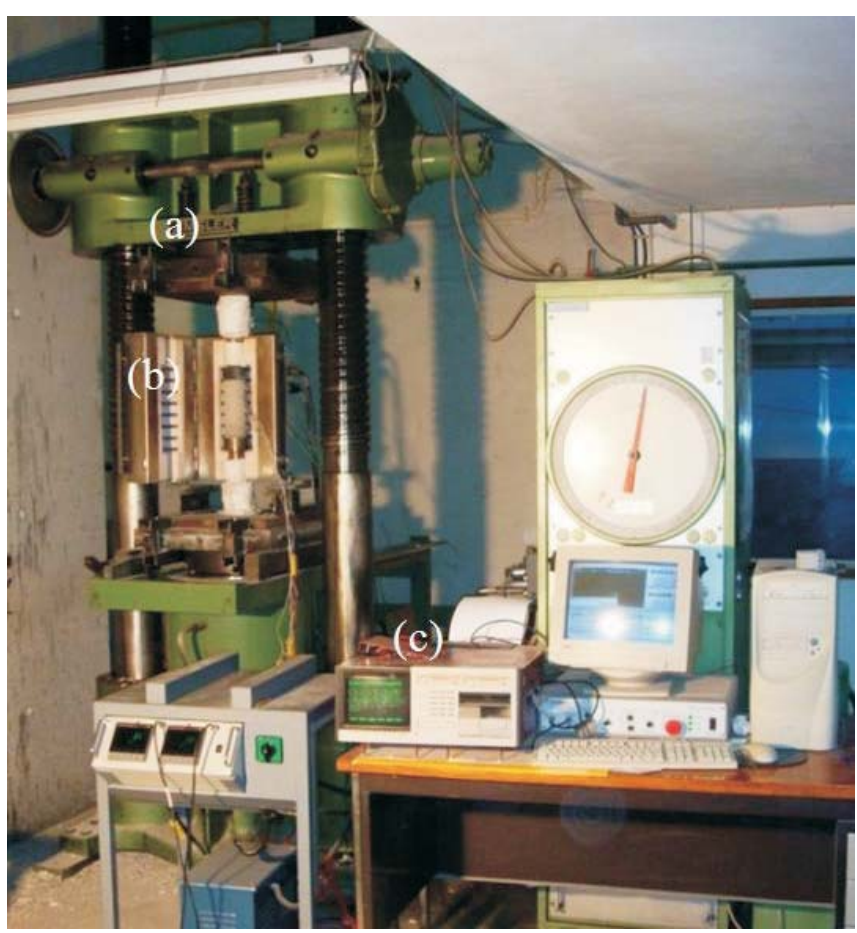

Fig. 1: Test system 


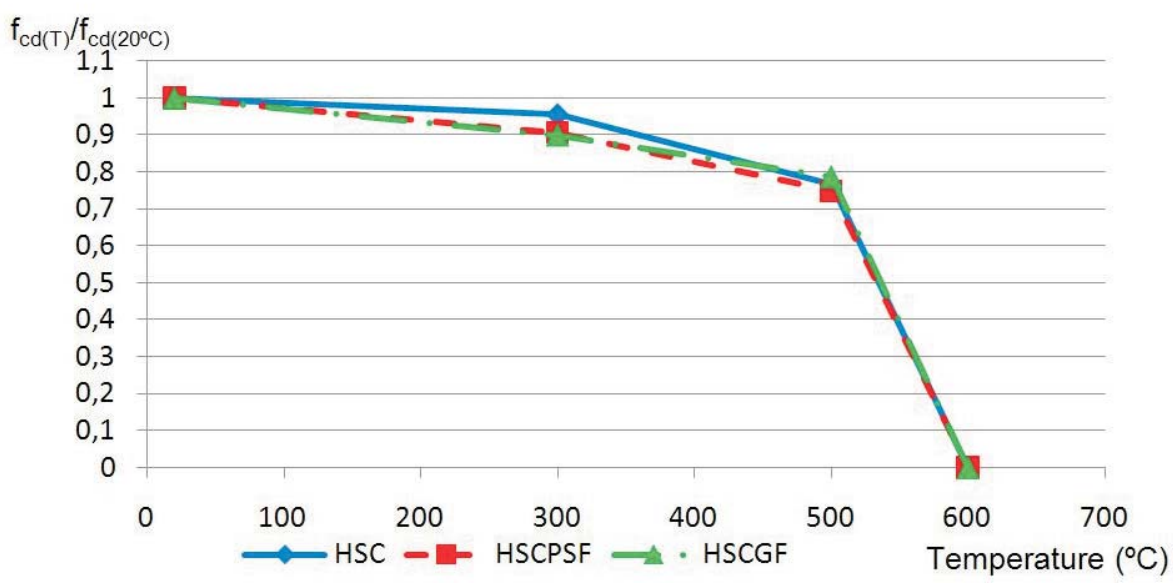

Fig. 2: Concrete compressive strength vs maximum temperature

inside and outside the specimen, given by thermocouples at the same level, was also ascertained. This difference should not be greater than $20^{\circ} \mathrm{C}$.

\section{Results}

Fig. 2 shows a graph plotting the variation of concrete compressive strength vs the maximum temperature that the specimens were subjected to in the experimental tests.

In tests carried out up to $300^{\circ} \mathrm{C}$, all specimens had a slight loss of strength. The HSC samples had a strength loss of $5 \%$ while the HSCPSF and HSCGF samples lost $10 \%$.

In the $500{ }^{\circ} \mathrm{C}$ tests, the HSC and HSCPSF specimens lost about $30 \%$ while the HSCGF samples lost approximately $26 \%$ of their strength at room temperature.

In the maximum temperature tests, $600{ }^{\circ} \mathrm{C}$, all the specimens collapsed before temperature stabilization. This may indicate that the initial compressive load applied to the specimens was excessive for this temperature.

There was a less explosive failure in the HSCPSF specimens, which confirms that steel fibers achieve a more ductile concrete.

Explosive spalling was not observed in any of the heating-cooling tests, only some cracks. Cracking was worse for tests up to $500{ }^{\circ} \mathrm{C}$. At this temperature, the HSCSPF specimens suffered exfoliation at the top.
In $300{ }^{\circ} \mathrm{C}$ tests the HSC specimens showed only some surface cracking.

\subsection{Brazilian Tests}

Tests to assess the stress-strain behavior of polypropylene fiber reinforced high performance concrete at ambient temperature $\left(27^{\circ} \mathrm{C}\right)$ and at high temperatures of 400, 650 and $900^{\circ} \mathrm{C}$, were carried out in COPPE's Laboratory of Structures at the Federal University of Rio de Janeiro, Brazil [6].

The residual compressive strength and elastic modulus were determined after the concrete was subjected to a heating and cooling process.

The role of polypropylene fiber in controlling the spalling of high performance concrete (HPC) was also investigated.

\section{Concrete composition}

The concrete was made with Portland cement (CPIII-40), sand with a fineness modulus of 2.70 , crushed syenite with a maximum size of $9.50 \mathrm{~mm}$ and a specific weight of $2.70 \mathrm{~g} / \mathrm{cm}^{3}$, naphthalene sulfonate based superplasticizer (SP) with a total amount of solid particles of $40 \%$ and silica fume. The polypropylene fibres (PF) were $40 \mathrm{~mm}$ long and had a specific weight of $0.91 \mathrm{~kg} / \mathrm{dm}^{3}$ and an elastic modulus of $3500 \mathrm{MPa}$.

Table 3: Mix proportions for the HPC tested (per $\mathrm{m}^{3}$ )

\begin{tabular}{|l|c|c|c|c|c|c|c|}
\hline \multicolumn{1}{|c|}{ Series } & $\begin{array}{c}\text { Cement } \\
{[\mathrm{kg}]}\end{array}$ & $\begin{array}{c}\text { Silica } \\
{[\mathrm{kg}]}\end{array}$ & $\begin{array}{c}\text { Sand } \\
{[\mathrm{kg}]}\end{array}$ & $\begin{array}{c}\text { Agg. } \\
{[\mathrm{kg}]}\end{array}$ & $\begin{array}{c}\text { Water } \\
{[\mathrm{l}]}\end{array}$ & $\begin{array}{c}\text { SP } \\
{[\mathrm{l}]}\end{array}$ & $\begin{array}{c}\text { Fibres } \\
{[\mathrm{kg}]}\end{array}$ \\
\hline C65 & 365 & 37 & 780 & 857 & 156 & 8.30 & - \\
\hline C85 & 414 & 42 & 694 & 895 & 151 & 8.49 & - \\
\hline C65PF0.25 & 365 & 37 & 780 & 857 & 156 & 8.30 & 2.28 \\
\hline C65PF0.5 & 365 & 37 & 780 & 857 & 156 & 8.30 & 4.56 \\
\hline C85PF0.25 & 414 & 42 & 694 & 895 & 151 & 8.49 & 2.28 \\
\hline C85PF0.5 & 414 & 42 & 694 & 895 & 151 & 8.49 & 4.56 \\
\hline
\end{tabular}




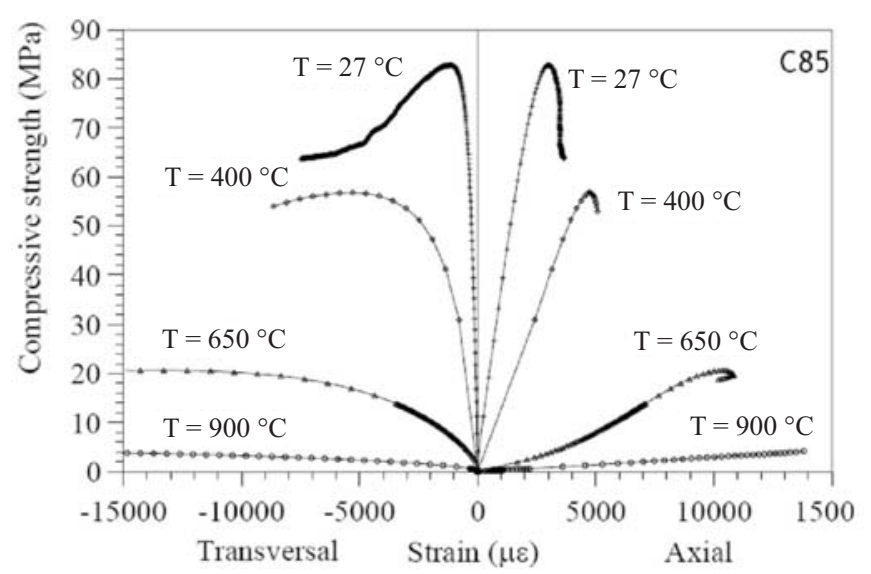

(a)

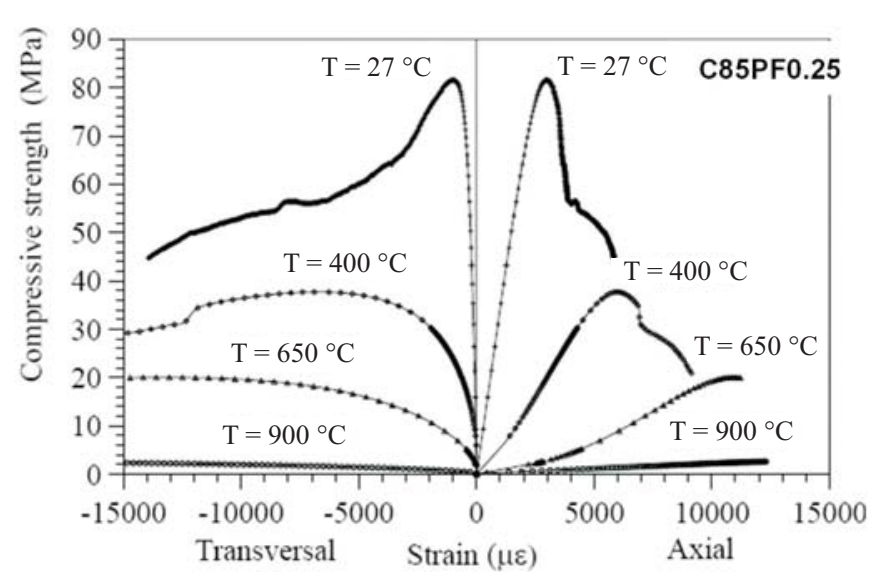

(b)

Fig. 3: Compressive stress-strain curves at room temperature after exposure to high temperatures: (a) Concrete series C85; (b) Composite series C85PF0.25

The mixtures were produced so as to reach compressive strength levels of $65 \mathrm{MPa}(\mathrm{C} 65)$ and $85 \mathrm{MPa}(\mathrm{C} 85)$ at 28 days. They were reinforced with $0.25 \%$ and $0.5 \%$ by volume of polypropylene fibers (C65PF0.25/C85PF0.25 and C65PF0.5/ C85PF0.5 series, respectively).

The mix proportions of the mixtures are summarized in Table 3 .

\section{Specimens and test procedure}

The compression tests were carried out on cylindrical specimens $100 \mathrm{~mm} \times 200 \mathrm{~mm}$. A $2500 \mathrm{kN}$ MTS compression machine was used, at a loading rate of $0.00078 \mathrm{~mm} / \mathrm{s}$. Three samples were tested for each mixture. Average values were taken as representative for each analyzed mixture.

Prismatic specimens $(150 \mathrm{~mm} \times 260 \mathrm{~mm} \times 100 \mathrm{~mm})$ were used in the spalling and total porosity studies. They were heated in a computer-controlled electric furnace at a rate of $10{ }^{\circ} \mathrm{C} / \mathrm{min}$. Three maximum temperatures $\left(400{ }^{\circ} \mathrm{C}, 650{ }^{\circ} \mathrm{C}\right.$ and $900{ }^{\circ} \mathrm{C}$ ) were chosen. Once the peak temperature was reached it was maintained for one hour and then cooled to room temperature at a rate of $(0.4-0.5)^{\circ} \mathrm{C} / \mathrm{min}$.

Total porosity was measured by means of water absorption tests on cylindrical specimens $(60 \mathrm{~mm}$ in height, with a diameter of $25.4 \mathrm{~mm}$ ) extracted from the prismatic samples.

\section{Results}

Typical compressive stress-strain curves for the plain and PF reinforced HPG matrices at room temperature and after exposure to high temperatures are presented in Fig. 3.

At room temperature, the addition of small volume fractions of PF to the concrete did not significantly change the behavior in compression of the matrices.

The results for the specimens that were subjected to temperatures of $400^{\circ} \mathrm{C}$ show that the PF HPC specimens suffered a more pronounced loss of strength and rigidity than the plain HPC specimens. At $650{ }^{\circ} \mathrm{C}$ and $900{ }^{\circ} \mathrm{C}$ all concrete specimens experienced a similar strength and rigidity loss, regardless of the presence of fibers in the mixtures.

The poor behavior of the PF concrete specimens is associated with the melting of polypropylene fibers at about $170^{\circ} \mathrm{C}$. A slight dilatation of about $10 \%$ [3] of the polypropylene occurs during melting, which generates extra pore-pressure in the concrete and leads to a higher crack density than that observed in the plain concrete. The fiber beds left in the matrix after melting may also help in the local nucleation of cracks as they have sharp angles, favoring the propagation of microcracking.

In this study, spalling was observed in C85 prismatic concrete samples for the $400{ }^{\circ} \mathrm{C}$ temperature series. The spalling occurred at about $200{ }^{\circ} \mathrm{C}-220{ }^{\circ} \mathrm{C}$. The addition of $0.25 \%$ by volume of $\mathrm{PF}$ to the $\mathrm{C} 85$ matrix prevented concrete spalling.

\section{Conclusions}

In the Portuguese studies, it could be concluded that the inclusion of PF fibers in the concrete compositions prevented spalling. The specimens with steel and polypropylene fibers performed better than those with glass fibers. A small detachment of surface concrete was observed in the glass fiber specimens.

A more explosive rupture occurred in specimens without fibers and in those with glass fibers. The benefit of steel fibers in controlling cracking was confirmed.

The incorporation of shorter steel fibers and a small amount of polypropylene fibers conferred greater strength on the concrete specimens.

In the Portuguese compression tests the concretes with glass fibers exhibited behavior quite similar to that of the specimens with polypropylene and steel fibers. The loss of strength of HSCGF specimens at high temperatures was only slightly lower than for the HSCPSF specimens. It was concluded that glass fibers did not improve concrete performance at high temperatures. However, further studies with this type of fiber are needed, since only a small number of tests were carried out in this study.

In the Brazilian studies it was concluded that at high temperatures the PF HPC specimens showed a more pronounced strength and rigidity loss than the plain HPC specimens. The increase in porosity was also higher for the PF HPC. This behavior can be associated with melting of $\mathrm{PF}$ at about $170^{\circ} \mathrm{C}$.

Another conclusion from this study was that the addition of PF to the C85 matrix prevented concrete spalling. 
Given these findings, we can state that PF prevents the spalling of concrete. These fibers melt at approximately $170{ }^{\circ} \mathrm{C}$ and are then partially absorbed by the microcracked cement matrix, leaving a pathway for gas to dissipate and so reducing water vapor pore pressure.

\section{References}

[1] Kalifa, P., Menneteau, F., Quenard D.: Spalling and Pore Pressure in HPC at High Temperatures, Cement and Concrete Research, Vol. 30 (1999), p. 1915-1927.

[2] Khoury, G. A.: Effect of Fire on Concrete and Concrete Structures. Prog. Struct. Engng Mater., Vol. 2 (2000), p. $429-447$.

[3] Kalifa, P., Chene, G., Galle, C.: High-Temperature behaviour of HPC with Polypropylene Fibres. From Spalling to Microstructure, Cement and Concrete Research, Vol. 31 (2001), p. 1487-1499.

[4] Santos, S., Rodrigues, J. P.: Spalling on Concrete Structures, Proceedings of the National Conference on Structural Concrete, 2008, Guimarnes, Portugal.

[5] Recommendations of RILEM TC 200-HTC : Mechanical Concrete Properties at High Temperature - Model- ing and Applications. Materials and Structures, Vol. 38 (2005), p. 913-919.

[6] Velasco, R. V., Toledo, R. D., Fairbairn, E. M. R., Lima, P. R. L., Neumann, R.: Spalling and Stress-Strain behaviour of Polypropylene Fibre Reinforced HPC after Exposure to High Temperatures.

Susana Otero Santos

e-mail: susana.otero.s@gmail.com

João Paulo C. Rodrigues

Faculty of Science and Technology of University of Coimbra, Portugal

Romildo Toledo

R. V. Velasco

Federal University of Rio de Janeiro Department of Civil Engineering, COPPE Rio de Janeiro, Brazil 